\title{
Crecimiento urbano de la ciudad capital de La Rioja, Argentina, 1970-2011. Análisis de riesgos
}

\author{
Manuel Mamani* \\ Raquel Brito**
}

Recibido el 11 de marzo de 2015; aceptado el 24 de marzo de 2015

\begin{abstract}
The population increasing in the larger population centers, such as the main cities of a State, was due to the migration from the inland territories, looking for a better life quality, the generational growth and the assumption that what people was looking for, was not sustainable at their home. This situation urgently brought the obligation and the need to provide housing solutions to this demand in several ways. Consequently, the private development and the launch of federal programs were encouraged by the government focused in building neighborhoods to satisfy the demand. All this took place, like elsewhere, in La Rioja city. Because of the need and hurry, it is estimated that there were not a strategic planning for the territorial occupation. This article underlines the need of the information, at least the geomorphological one, to avoid having adverse consequences when weather events occur in the area of interest. The public information and land use background in the area to urbanize, led to the conclusion that some site locations were not appropriate, since when an extraordinary phenomenon comes up, as significant rainfalls, the buildings have undesired consequences. This situation is understandable taking in consideration the stormwater runoff in streets, especially in the rainy season resulting in floods, road and street blockades, deprivation of essential services, etc. The analysis of historical aerial photographs of the 1960s, satellite data provided by the Landsat series and updated existing data in Google Earth were some elements used to achieve to the conclusions.
\end{abstract}

Key words: population growth, satellite image; risk.

* Professors - Researchers from National University of La Rioja. Instituto Argentino de Nivología, Glaciología y Ciencias Ambientales; Av. Ruiz Leal s/n Parque General San Martín, 5500, Mendoza, Argentina, correo electrónico: mmamani@mendoza-conicet.gob.ar

** Professors - Researchers from National University of La Rioja. 


\section{Resumo}

O aumento da população nas grandes cidades, como as capitais estaduales, foi devido a migração do interior em busca de melhor qualidade de vida, mas também por causa do crescimento geracional e o reconhecimento de que nas cidades de origem isso não era sustentável. Essa realidade trouxe a obrigação e a necessidade de fornecer soluções habitacionais para a demanda da população de diferentes tipos, em conjunto com a urgência que isso significa. Assim a administração central encoragou a urbanização particular, além dos programas federais que foram lançados para a construção de bairros para atender essas necessidades. Foi o que aconteceu, como em outros lugares, na cidade capital de La Rioja. Estima-se que não houve planeamento estratégico da ocupação territorial, por causa dessa necessidade e urgência. Este artigo destaca que é necessario utilizar informação, pelo menos da geomorfologia, para evitar ter consequências adversas quando eventos climáticos ocorrem na área de interesse. Informações públicas e o histórico do uso da terra na área para urbanizar, levaram à conclusão de que a localização dos locais onde isso ocorreu não eram os mais adequados, desde que toda vez que ocorre um fenômeno extraordinário, como chuvas abundantes, consequências inesperadas acontecem nas contruções. A situação é compreendida observando e tomando como exemplo as avenidas de águas pluviais causadas por fortes chuvas, especialmente na epoca de maior freqüencia, que produzem inundações, estradas interditadas e estragadas, falta de serviços essenciais como energía e agua potável, etc. Além, a análise de fotografias aéreas históricas da década de 1960, dados de satélite fornecidos pela série Landsat e os dados existentes atualizados no Google Earth foram ferramentas para obter estas conclusões.

Palavras-chave: crescimento populacional, imagens de satélite, riscos.

\section{Resumen}

El incremento de los habitantes en los mayores centros poblados, como son las capitales de provincia, fue debido a la migración desde el territorio interior buscando mejor calidad de vida, pero también por causa del crecimiento generacional y el reconocimiento de que en sus lugares de origen aquello no era sostenible, esta realidad trajo la obligación y la necesidad de proveer con soluciones habitacionales la demanda de diversas maneras, acompañado de la urgencia que esto trae aparejado. De esa forma se alentó desde la administración central la urbanización privada, también se pusieron en marcha los programas estatales que están dirigidos a construir barrios para cubrir aquellas necesidades. Esto es lo que ocurrió, al igual que en otros sitios, en la ciudad de La Rioja, atribuible a la necesidad y urgencia, se estima que no hubo una planificación estratégica de la ocupación territorial. Este artículo pone de manifiesto que es necesario valerse de información, al menos de la geomorfología, para 
evitar consecuencias adversas cuando ocurren eventos climáticos en la zona de interés. Mediante informaciones públicas y recurriendo a los antecedentes del uso de suelo en la zona a urbanizar, se llegó a la conclusión de que el emplazamiento de los sitios donde ello se produjo no han sido los más adecuados, toda vez que cuando ocurre un fenómeno extraordinario, como abundantes precipitaciones, hay consecuencias no deseadas en las construcciones. Esta situación se entiende con observar y tomar como ejemplo las avenidas de aguas torrenciales causadas por las intensas lluvias, sobre todo en las épocas de mayor caída, dejando como consecuencia inundaciones, cortes de calles, privaciones de servicios esenciales etc., sirvieron para obtener estas conclusiones el análisis de las fotografías aéreas históricas de la década de los sesenta, la información satelital provista por la serie Landsat y culminando con los datos actualizados existentes en el Google Earth.

Palabras claves: crecimiento poblacional, imágenes de satélite, riesgos.

\section{Introducción}

Durante el transcurso de los años 1970 al 2011, el tejido urbano de la ciudad de La Rioja ha experimentado un notable crecimiento edilicio en forma asimétrica, necesario y coherente con el incremento en la cantidad de habitantes por la migración, pero también fruto del desdoblamiento familiar, como dato ilustrativo se puede mencionar que en los últimos 50 años el aumento de habitantes, que en el año 1960 era de 39,597 pobladores pasó a 180,995 en el 2010. El mayor incremento se produjo desde el año 1991 al 2011 donde hubo una evolución de la cantidad de habitantes, en la ciudad, de 40,415 (Datos de censos nacionales). Se atribuyen estas cantidades, en el primer caso, provocado por la migración del interior provincial hacia los centros urbanos; por el otro, la evolución propia de las ciudades y el crecimiento demográfico y en el caso particular, las crisis económicas nacionales de los años 1990 y 2001. Esta situación trae aparejada la necesidad de nuevos asentamientos para estos vecinos y de contar con los servicios esenciales como transporte, energía, recolección de residuos, entre otros, concomitante con ello y para cumplimentar el reconocimiento, se hace necesario hacer un análisis del uso del suelo en aquellos sitios y la carga a la que será sometido el medio ambiente por los efectos contaminantes y en general, lo que significa, la modificación del ecosistema. A partir de allí debe tenerse en cuenta la disposición de los residuos sólidos y líquidos urbanos, así como también en algunos casos industriales y las secuelas que pueden dejar sobre los factores ambientales (suelo, agua superficial y subterránea, aire). En esta situación se puede presumir que no se pusieron en práctica los instrumentos de planificación que implican cambios socio-territoriales importantes, principalmente en zonas del norte-oeste y sur de la ciudad, de modo de aplicar las normas existentes, las consecuencias inmediatas, por esa ausencia, fue la limitada capacidad para asumir la sostenibilidad del crecimiento 
urbano. También en esa carencia de planificación se ha producido la insuficiente distribución de áreas verdes, necesarias para un verano habitualmente intenso por las temperaturas de la zona.

La velocidad del crecimiento, por los resultados observados, ha impedido una planificación consensuada con los responsables de proveer aquellos servicios, más aún a tener en cuenta, en ese planeamiento, que el asentamiento de la ciudad está geográficamente ubicado sobre una superficie irregular, esto es así si se tienen en cuenta los desniveles del terreno que están formando un plano alabeado, con los mínimos en el sector Norte y el Sur y en descenso desde el Oeste (Las Padercitas $657 \mathrm{msnm}$ ) hacia el Este, (Ruta Nacional 38, 460 msnm) en una distancia de 10km, (véase Figura 5). Se debe considerar que el emplazamiento del sitio de la ciudad capital se encuentra en el denominado Cono Aluvial de La Rioja, donde desde el subsuelo se extrae el agua potable para la población, como así también para los cultivos cercanos a la ciudad, en especial los emprendimientos olivícolas.

En capital de La Rioja existen 56,269 cuentas de usuarios de agua y cloacas, la población se abastece con agua que proviene del dique Los Sauces (Figura 1) mediante el acueducto que abastece la zona Oeste. En el resto de la ciudad existen distribuidas 60 perforaciones, mediante el sistema de obtención de agua subterránea (perforaciones) que tienen alrededor de 300 metros de profundidad y a través de un método electromecánico se extrae agua, que potabilizada en el lugar se envía a la red abasteciendo el $70 \%$ de la ciudad restante. La cobertura de los suelos involucrados en la ciudad de La Rioja puede verse en la Figura 1, que muestra sucintamente la geomorfología.

Las aguas servidas de la ciudad de La Rioja, provenientes de su uso consuntivo, son recolectadas por una red cloacal y conducidas por una extensa red de colectores ubicados bajo la superficie hacia las estaciones de bombeo y plantas depuradoras, en donde se les proporciona el tratamiento adecuado antes de ser depositadas en los cuerpos colectores, las redes en su mayoría están compuestas de cañerías de PVC, hormigón comprimido y asbesto-cemento. La longitud de la red suma $443 \mathrm{~km} ; 35,720$ conexiones domiciliarias; 3,700 bocas de registro y dos estaciones elevadoras de líquidos cloacales (Aguas Riojanas, Sociedad Anónima con Participación Estatal Mayoritaria, SAPEM). De esta manera se ha logrado que la circulación de aguas contaminadas por el subsuelo de la ciudad sea mínima.

Este artículo tiende a analizar y demostrar gráficamente desde las imágenes satelitales que no se ha contado con una planificación previa, de este modo las obras habitacionales han sido dirigidas en trazados sensibles a ser afectadas por distintos factores. Para realizar este artículo se ha contado con información histórica de fotografías aéreas, de periódicos locales que muestran la realidad urbana cada vez que los fenómenos meteorológicos dejan secuelas sobre la ciudad, como las crónicas de eva- 
cuaciones, hundimientos habitacionales o aislamientos temporales de zonas críticas, como así también información proveniente de organismos públicos. Como dato descriptivo conviene subrayar que la ciudad de La Rioja, capital de la provincia homónima, se ubica en el centro-oeste de la República Argentina (29 24' 48.83' S - $66^{\circ}$ $51^{\prime} 21.24^{\prime \prime}$ O, $\left.511 \mathrm{msnm}\right)$. Está fundada sobre un cono aluvial proveniente de la vertiente oriental de la sierra de Velasco y es la descarga de la cuenca Huaco Sanagasta que es la mayormente proveedora del agua subterránea para el consumo humano bebida y la industria. El clima de la región es árido y seco en el llano (el agua caída por año es de $360 \mathrm{~mm}$ de lámina), incrementando su humedad hacia la sierra, donde las precipitaciones tienen cierta importancia. La provisión de agua para la población, en la ciudad depende de la precipitada en la sierra y en el cono mismo, la cual es superficialmente escurrida e infiltrada y extraída mediante perforaciones.

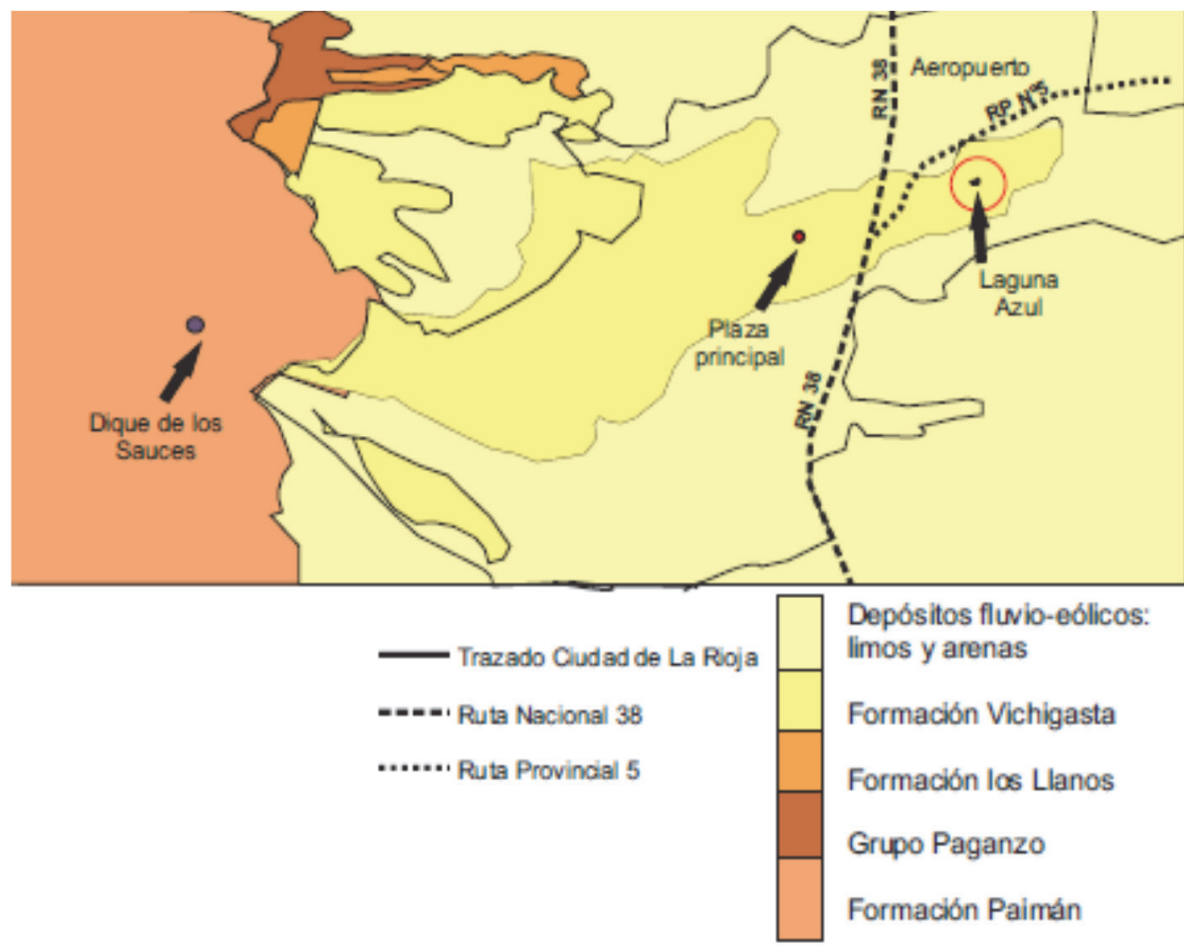

Figura 1. Suelos de la ciudad de La Rioja. Formación Vichigasta, Pleistoceno (Francisco Fidalgo, 1963); Formación Los Llanos, Cenozoico terciario, Mioceno (Ezpeleta, M. et al., 2006); Formación Paganzo. Paleozoico Pérmico (Miguel Archangelsky, 1996); Formación Paimán, Paleozoico, Ordovícico temprano (Varela, Ricardo, et al., 2008). 


\section{Materiales}

Se ha utilizado, como base de análisis, la información obrante en las imágenes satelitales, en las crónicas periodísticas y los antecedentes fotográficos recopilados que fueron utilizados en este artículo y que sirven además de evidencia y de ilustración del texto. En primera instancia sirvieron, como antecedente histórico, las fotografías aéreas provenientes del Instituto Foto Topográfico Argentino (IFTA), que una vez digitalizadas se procedieron a referenciar con las imágenes más modernas provistas por los satélites Landsat en un tiempo intermedio (Figura 2) y el Google Earth en cercano al presente (Figura 4), además se cuenta con los resultados de los Censos Nacionales y el análisis estadístico mostrado en la Figura 5. Luego del procesamiento de estas informaciones provistas por las imágenes, y la validación de campo efectuada por los autores, hay una clara demostración de que este crecimiento no ha sido armónico, como debería haber sido si se utilizan como sentido de crecimiento, las direcciones radiales de la ciudad capital. Como causa especial de esta anomalía de crecimiento se estima, la disponibilidad de terrenos fiscales o de bajo valor agregado en los alrededores de la ciudad capital, en esta situación se ha preferido en mayor medida las áreas hacia la zona Sur, interesaría saber cuál ha sido, de estos, no conocido, el argumento oficial de esa dirección de crecimiento.

\section{Análisis de los antecedentes y los datos}

Desde la fotografía aérea con el grado de resolución de las fotocartas de 1:50,000 y los pares de vuelo 1:20,000, se ha construido la imagen a partir de mosaicos que contiene la ciudad de La Rioja y que han sido procesadas a escalas semejantes con las que son factibles de conseguir de los satélites, se puede observar que las superficies cultivadas establecidas, en primera instancia, hacia el Oeste de la ciudad, han sido reemplazadas por la urbanización modificando el uso del suelo y el paisaje natural, acción realizada seguramente para lograr mejor bienestar, en especial cuando se trata del clima veraniego; por el bajo valor de la tierra en aquellos momentos, y también por el aumento en las retribuciones de una clase social que demandó y permitió esa urbanización. Sin embargo la migración de la agricultura, hacia la zona Este de la RN 38, lleva consigo a una mayor profundidad de los estratos portadores de agua que encarece la producción, y además mayor exposición a la contaminación industrial y urbana, caso paradigmático es la llamada Laguna Azul, ubicada en las cercanías de la ciudad que era y es aún un depósito de aguas servidas con contenido incluso de metales pesados y que no ha sido remediado en su totalidad, habiendo permitido, por la presión hidrostática, la infiltración hacia los acuíferos subyacentes y observado, aguas abajo, en las perforaciones existentes, de notable importancia para el consumo humano, la agricultura y la industria (Mamani et al., 2010, 2013). 
El límite sur de la ciudad, establecida en la fotografía, en la década de los sesenta, era en la dirección Oeste-Este, la Avda. Laprida, hoy llamada Presidente Menem. Según los datos provistos por los censos nacionales desde 1991 en adelante y observado luego en las imágenes mencionadas, la dirección del crecimiento inmobiliario horizontal preponderante fue hacia sur de la capital provincial. La experiencia denota que para el desarrollo de una zona, es de rutina rodear a una edificación convocante utilizada como núcleo donde se manifiesten acciones diversas, sobre ese motivo es necesario incorporar en el análisis el establecimiento de la construcción de la Universidad Nacional de La Rioja (UNLaR) que cumplió con aquel cometido. Esta acción tuvo lugar durante las etapas de traspaso a la jurisdicción nacional en el año 1994; en 1996, cuando se da comienzo a las obras de los edificios de la ciudad universitaria; y 1998 es cuando se produce el traslado a ese sector de la ciudad desde el actual Centro Administrativo, antiguo Hogar Escuela, identificado en la Figura 4, sumado a ello se produce la circunstancia de la implementación de carreras universitarias que se incrementaron, y el aumento de la matrícula de los alumnos, es posible de explicar como una de las principales causas, el crecimiento habitacional hacia ese sector en cercanías del mayor sitio educativo de la provincia, entre otros beneficios, por la necesidad de alojamiento de los alumnos provenientes del interior de la provincia, de estados vecinos y de otros países.

Sin embargo sobre esta disposición de las nuevas edificaciones, se deben tener en cuenta los riesgos naturales que implicaba el desarrollo hacia los sectores considerados. Entre ellos se pueden establecer, el de las aguas escurridas por el ríos provenientes de la descarga del dique Los Sauces, que tienen sentido preferencial por donde existe el mayor gradiente, que son los límites externos del cono aluvial, se debe tener en cuenta además, el producido por las lluvias de verano que llegan en algunos casos a ser tormentas por su intensidad, que en mayor medida se establecen en esa zona debido a la altura y a las condiciones meteorológicas que favorecen las precipitaciones, facilitado por la topografía, que en este caso escurren (véase Figura 1), con preferencia de canalización hacia los extremos más bajos del cono es decir hacia el noreste y sureste del Cono Aluvial de La Rioja, (Figura 1) siguiendo la mayor pendiente (corte A-A', Figura 5).

Es evidente que bajo las circunstancia de haberse incluido como prioritaria el desarrollo urbano de esos sitios, se entiende no fue suficiente la planificación o no hubo conclusión en el proyecto destinado a construir los nuevos complejos habitacionales. Es importante observar la falta de obras de conducción en avenidas principales para el escurrimiento del agua de lluvias, razón que tiene como consecuencia socavar los terrenos y la tendencia natural a reintegrarse a los antiguos cauces, visto con las fuertes precipitaciones de los últimos años. Esto era previsible y las consecuencias de aquel hecho serían inundaciones en aquellos nuevos barrios además de contribuir a debilitar las fundaciones de las edificaciones. 
Se hace necesario destacar dos ejes significativos, el primero es preciso exponerlo debido a que se estima que el mayor desarrollo hacia aquel sector considerado (zona sur de la ciudad), tuvo mucho que ver con la necesidad de estudiantes y familias de estar cerca a las instalaciones de la UNLaR, prueba de ello son los numerosos emprendimientos edilicios que se han establecido en esa zona y que aún sigue un leve crecimiento en ese sentido.

Como segundo aspecto y con el objeto de disminuir los riesgos concomitantes, tal como surge de este artículo, será necesario controlar y/o planificar la canalización de los antiguos cursos de agua, la construcción de defensas aluvionales para cuando se produzcan las precipitaciones lluviosas extraordinarias, asimismo, se considera sustancial hacer los estudios de suelos en las zonas donde se han establecido los nuevos barrios para una mayor eficiencia de las fundaciones, entre otros y prever las obras de servicios necesarias para aquellas edificaciones y/o las futuras realizaciones. Esto último, es una recomendación técnica a tener en cuenta por el proceso espontáneo de densificación de las construcciones, que están siendo observadas en la zona y que asegura la forma que debe comprenderse y tratarse, como entes en cambio permanente.

\section{Descripción de las Figuras}

En la Figura 2, es posible observar el área cubierta por el núcleo urbano en la década de los sesenta, separado de la sierra por un segmento establecido desde el contacto del llano con la sierra de Velasco (Las Padercitas), hasta la ciudad, este se encuentra cubierto por parcelas de cultivos, donde las escasas edificaciones siguen el canal de riego (se observa sobre la Avda. Facundo Quiroga) hasta llegar al centro comercial. Es notable observar en la fotografía aérea, aquellos cauces secos que tienen sus trazas por el Norte $(420 \mathrm{msnm})$ y el sur $(490 \mathrm{msnm})$ de la ciudad, con intensa actividad en el caso de fuertes lluvias, consecuencia de los desagües provocados por los torrentes de agua en las precipitaciones intensas que es alimentado, además de la salida del río de Los Sauces, por las cuencas que se encuentran al Oeste de dicho cauce, de igual modo ocurre en el Sur, esto es entendible si se considera que los menores niveles del terreno se encuentran en esos sitios, y donde la mayor altitud está ubicada en el centro del cono aluvial (520msnm). En la observación de la imagen se encuentra que el área de cultivo incipiente se prolonga hacia el Este de la RN 38. El límite sur de la ciudad se observa por lo que hoy se identifica como la Avda. Menen, el Norte es más difuso, pero está limitado por la traza del cauce seco, esta geografía no se ha modificado, esto representa que las precipitaciones lluviosas que ocurren en el flanco este de la sierra tienen igual sentido de descarga. Asimismo el Oeste de la malla urbana este definido por la línea demarcada por el río Tajamar. En resumen el área que comprende a la ciudad se encuentra edificada y definida acorde con la población de ese momento. 


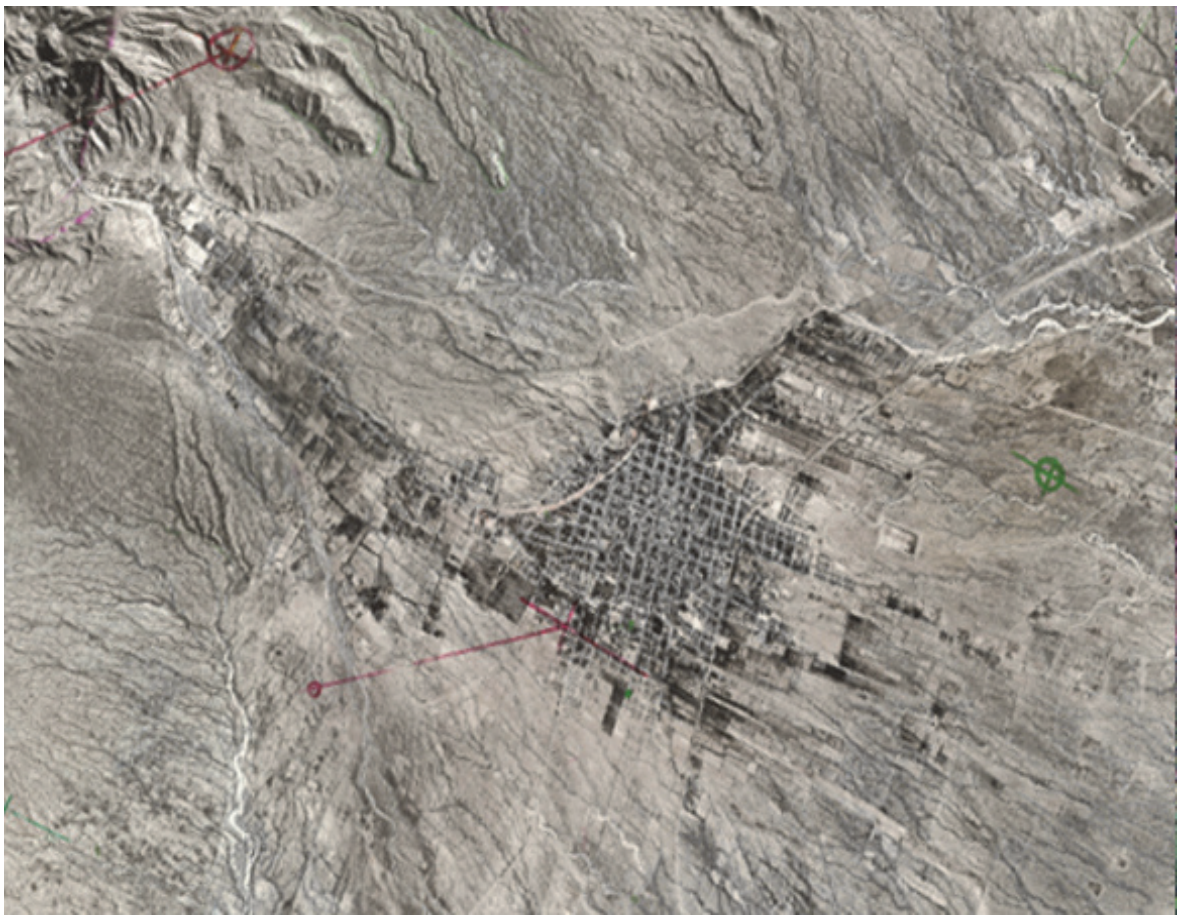

Figura 2. Ciudad de La Rioja, Argentina, 1968. Imagen digitalizada desde la fotografía aérea, (pares de vuelo y fotocartas), se observan los cauces de circulación de las aguas provenientes de las precipitaciones, hacia ambos costados del cono aluvial; hacia el $\mathrm{O}$ las parcelas de cultivo, y al centro la cuadrícula edilicia de la ciudad capital.

La Figura 3, proveniente del procesamiento de la información satelitaria que en este caso corresponde a la serie Landsat, se puede indicar con claridad la incorporación de las nuevas áreas cultivadas al Este de la RN 38, para identificarlas son figuras irregulares y en otros casos como círculos, en dependencia con la forma de riego, en general se tratan de plantaciones de olivos, producto de las facilidades que admitió la Ley de Promoción Industrial ( $\mathrm{N}^{\circ} 22.021 / 79$ y sus modificatorias), que ha permitido la instalación de industrias para la extracción de aceite con alto valor agregado, asimismo hay un mayor cubrimiento por viviendas entre la antigua ciudad y las trazas de los cauces de ríos secos. Se destaca un asentamiento inmobiliario entre la antigua ruta, hacia el Sur, que unía la ciudad con la localidad de Talamuyuna, de modo que se insinúa la tendencia de ese momento de ampliar la ciudad hacia esos sectores. El procesamiento en falso color compuesto, permite la observación de las laderas de la sierra de color verde, prueba de que es un área donde se producen las mayores caídas 


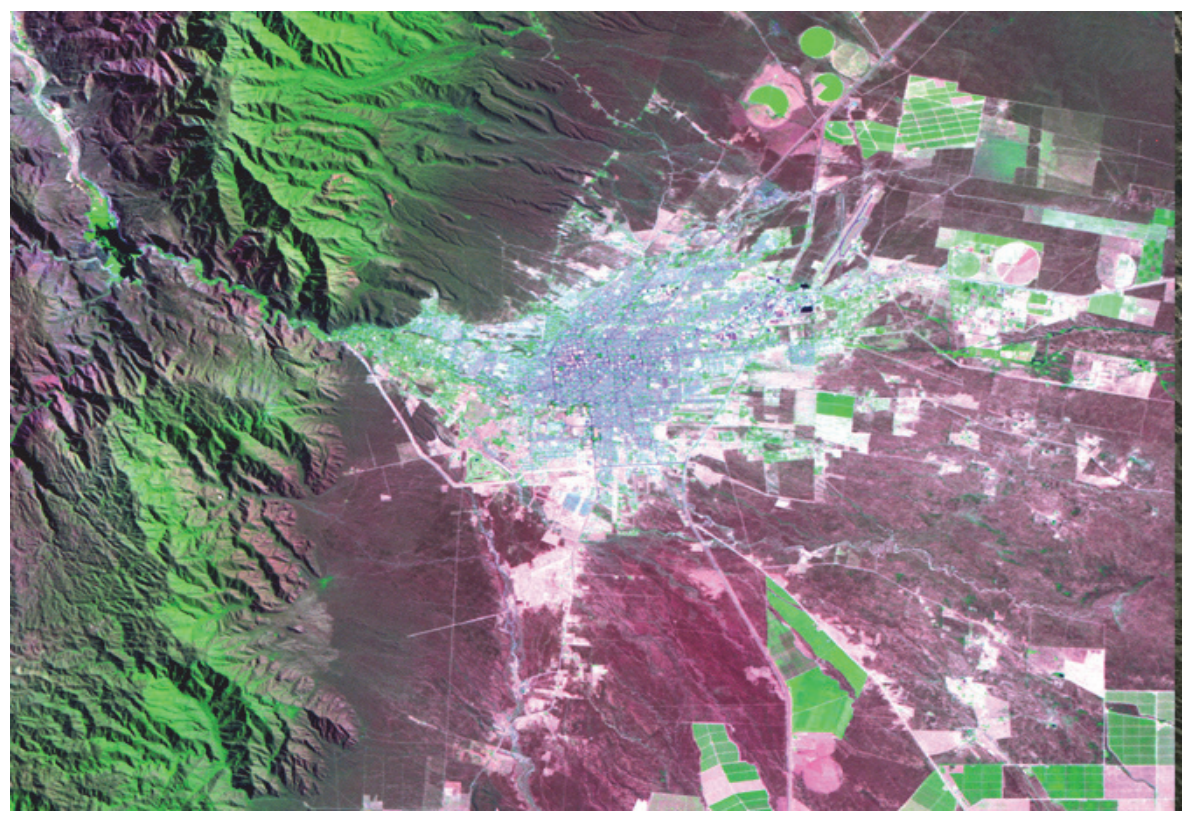

Figura 3. Ciudad de La Rioja, Argentina, 1995. Imagen proveniente del satélite Landsat procesado en falso color compuesto al objeto de resaltar la mancha urbana al centro, las superficies de cultivo hacia el E y SE, en el O se observa el reemplazo de las parcelas por la edificación, hacia el S la antigua RN 38, con sectores de evidente movimientos de tierra (colores claros) hacia donde fue dirigida el crecimiento de la ciudad de La Rioja.

de agua de lluvia, luego la vegetación abundante es una consecuencia de aquel aumento de las precipitaciones.

La Figura 4, extraída y procesada desde la información provista por el Google Earth del año 2013, la superficie urbanizada se ha extendido y los cauces secos han sido cubiertos por viviendas, mayormente hacia el Sur de la ciudad, en menor medida hacia el Norte. Se interpreta que la falta de obras concluyentes, es una de las causas que llevaron a esta situación de riesgo y el principal inconveniente es debido a los desniveles de la franja de estudio, donde se hacía necesario un mayor movimiento de suelos y que seguramente encarecía el financiamiento de las construcciones. Asimismo en el Este y noreste, hay un notable incremento de las áreas cultivadas que entre otras cuestiones demanda mayor agua desde los estratos subterráneos donde se encuentran los acuíferos productivos.

En la Figura 5, se han resumido, mediante la construcción de una traza que pasa por el borde este donde se encuentra la mayor densidad de urbanización de la ciudad, se puede apreciar, en las diferentes etapas donde se realizó el análisis, los incrementos 


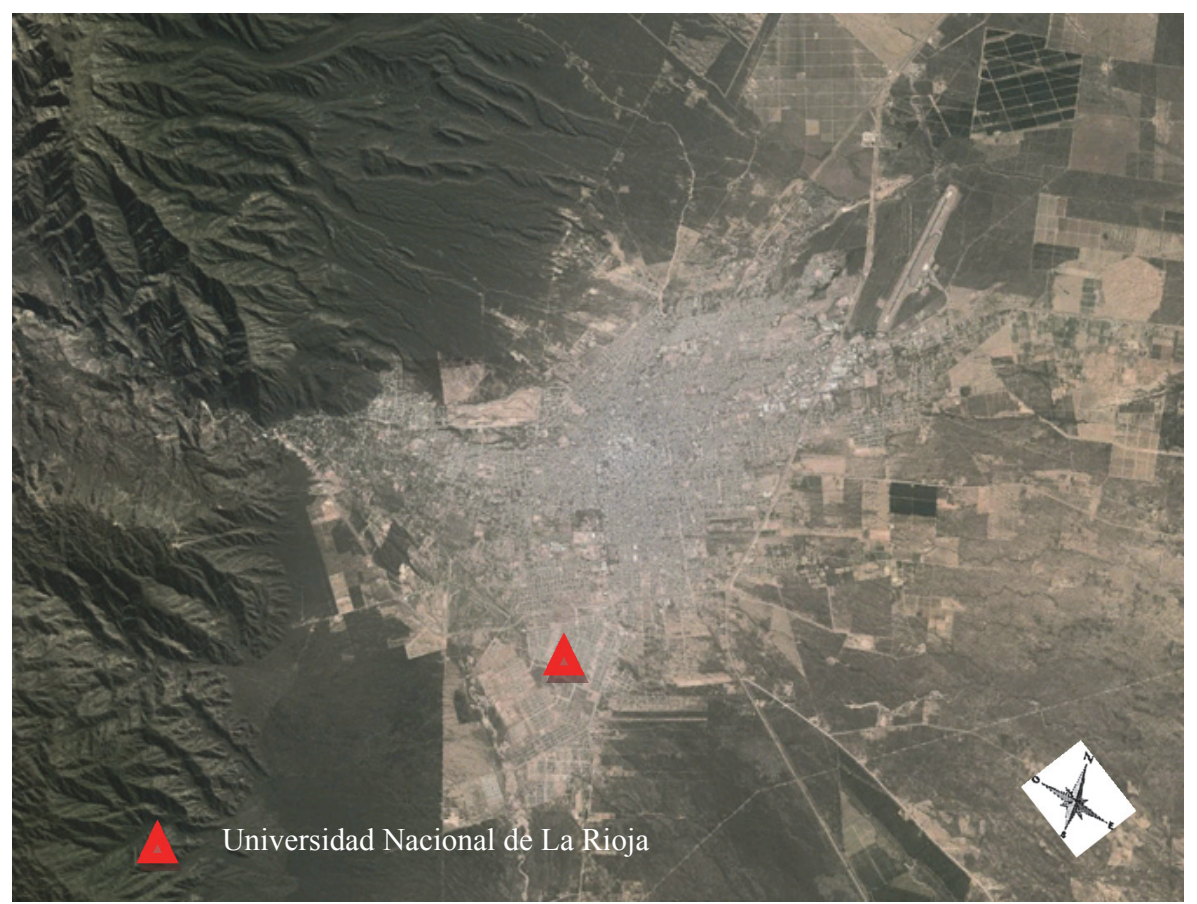

Figura 4. Ciudad de La Rioja, Argentina, 2013. Imagen del Google Earth, la Avda. de Circunvalación que tiene su traza del S hacia el NO de la ciudad, se encuentra totalmente cubierta por nivelaciones y edificaciones al igual que hacia el S. Los accesos hacia la capital han sido modificados en su traza y entre ellas la RN 38.

de la superficie que se han producido en la ciudad capital de la provincia de La Rioja, asimismo el perfil de alturas logrado a lo largo de la línea A-A', pone de manifiesto la irregular morfología del Cono Aluvial, destacándose los mayores gradientes de altura, con el menor nivel en los extremos Norte y Sur que facilitan y ordenan los desplazamientos de los caudales de agua en los momentos de precipitaciones intensas.

\section{Conclusiones}

La forma gráfica de análisis presentada en este artículo a través de la información extraída desde las imágenes provenientes de los satélites Landsat, la composición de lo provisto por el Google Earth, la digitalización de las fotografías áreas históricas, y la validación de terreno, sumado a las crónicas periódicas de los diarios locales, que describen la situación y las consecuencias emanadas cada vez que se presenta 

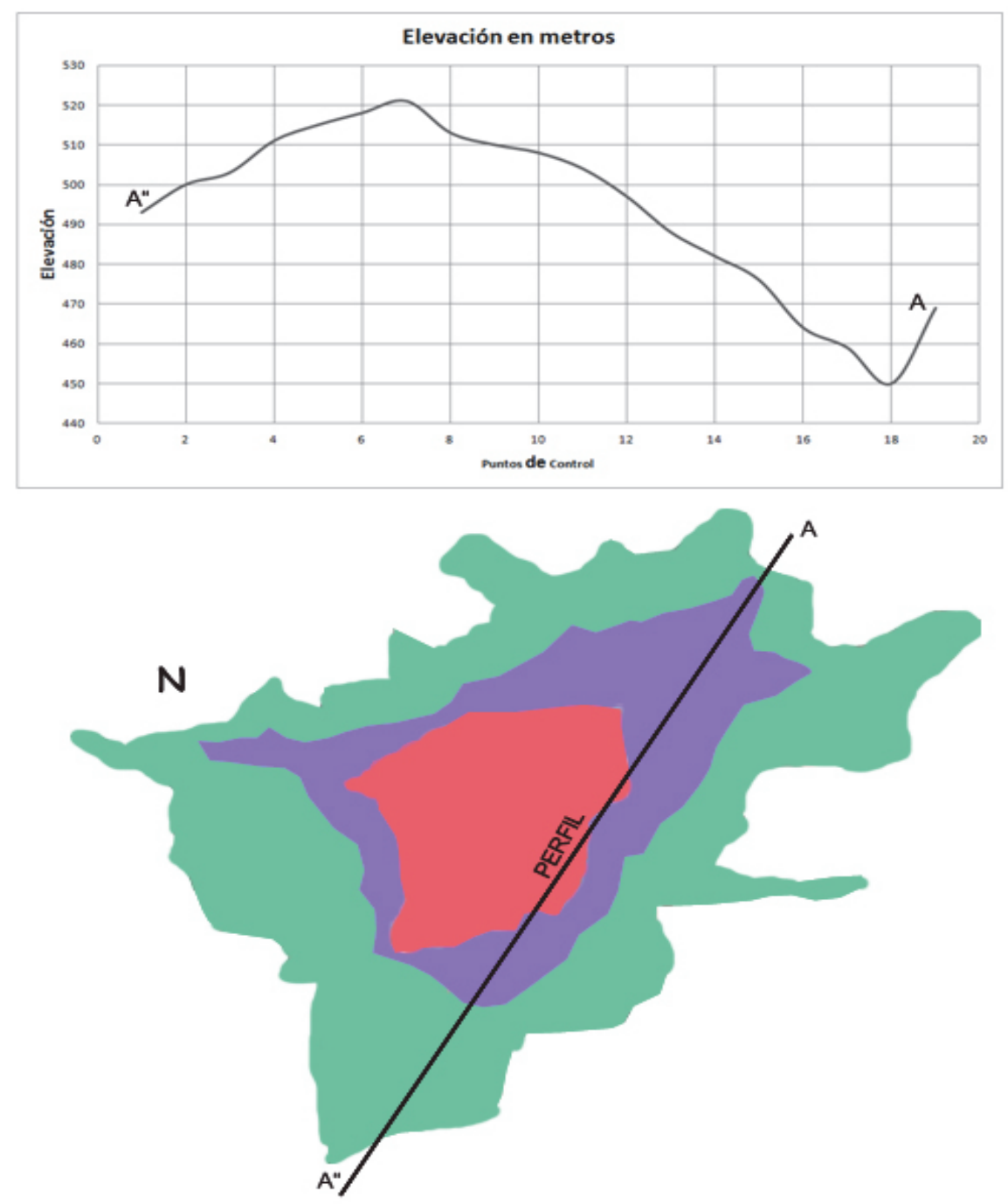

\section{CRECIMIENTO URBANO DE LA CIUDAD CAPITAL DESDE 1970-2013}

Figura 5. Arriba el perfil topográfico del Cono Aluvial de La Rioja A-A" con niveles menores hacia el $\mathrm{N}$ y el $\mathrm{S}$, muestra las envolventes de los crecimientos edilicios analizados en las tres etapas, la mayor superficie corresponde al 2013, el incremento de los espacios ocupados se ubicaron en el costado S-NO, y O-NE, del estado original, que es el sitio por donde escurren las aguas torrenciales de las precipitaciones lluviosas, que se potencian, cuando hay tormentas intensas. 
una fuerte precipitación de lluvia en el ámbito de la ciudad de La Rioja, los inconvenientes que causa en las viviendas que se encuentran establecidas en la periferia del principal núcleo urbano, permiten realizar un seguimiento de los modos de crecimientos de las áreas urbanizadas y más aún, en este caso, cuando se trata de una capital de provincia y las secuelas de este hecho singular, la colecta de datos, los antecedentes semejantes, animan un buen acopio de antecedentes que permiten describir la ausencia de planificación avalado con los resultados obtenidos. También se hace visible que los barrios donde se proyectan asentamientos, son instalados en sitios que no responden a un ordenamiento territorial, por lo que es importante una ordenada programación urbana, evitando en lo posible la ocupación de terrenos de riesgo, se debe asumir que este acto cumple funciones políticas y administrativas y debe ser implementado como una cuestión de estado teniendo en cuenta que va a servir para el crecimiento a corto, mediano y a largo plazo, los resultados van a redundar seguramente en adecuar los desarrollos económicos y sociales además de inscribir dentro de ello el aspecto ambiental, de forma tal de coordinar en forma consensuadas con todos los principales actores involucrados en el desarrollo de las ciudades que va a servir, en este caso, conseguir la eficiencia en lo que se denomina ocupación territorial vinculándose con la gestión ambiental en línea, de hacer una ciudad más sostenible y proyectar el impacto del evento sobre el entorno físico y social construido y por lo tanto especificar cuánto puede afectar a una comunidad.

Seguramente se va a necesitar, para un buen logro, la participación de los organismos académicos para la capacitación y en algunos casos la implementación de las políticas y prácticas catastrales, incluyendo además, lo relacionado con el urbanismo rural, los asentamientos humanos y desarrollos industriales o productivos, que asimismo sirven para cooperar en el financiamiento y la ejecución de estas estrategias, permite asimismo monitorear y reforzar el medio ambiente construido y la evaluación de las pérdidas.

Los planes de ordenamiento territorial enfrentan diversos problemas: interés público vs. interés privado; interés conservacionista $v s$. interés desarrollista; objetivos sectoriales de desarrollo $v s$. objetivos regionales/territoriales y presiones de poder frente a la toma de decisiones ordenadoras (Ordenamiento territorial y procesos de construcción regional, Ángel Massiris Cabeza).

En esta definición se debe centrar la discusión sobre la ocupación territorial de los espacios que pretenden ser utilizados para la urbanización, corresponde a los responsables políticos y económicos implementar las normas. 


\section{Bibliografía}

Archangelsky, Miguel, "Formación Paganzo Paleozoico Pérmico", El sistema Pérmico en la República Argentina y en la República Oriental del Uruguay, Academia Nacional de Ciencias de Córdoba, Argentina, 1996.

Diario El Independiente, "Las secuelas de la lluvia", año XLIV, edición № 20.823 Copegraf limitada Argentina, 2015, 14. Disponible en <http://www.elindependiente.com.ar/papel/hoy/archivo/noticias_v.asp?277357> (consultado el 26 de enero de 2015).

Ezpeleta, M., Dávila, F.M. y Astini, R.A., "Estratigrafía y paleoambiente de la formación Los Llanos (La Rioja): una secuencia condensada Miocena en el antepaís fragmentado andino central", Revista de la Asociación Geológica Argentina, vol. 61, núm. 2, 2006.

Fidalgo, Francisco, "Algunos rasgos tectónicos y geomorfológicos de la sierra de Sañogasta y Vilgo", Revista de la Asociación Geológica Argentina, tomo XVIII, 1963.

Mamaní, M.J.; Huespe, V.J. y Dematte, R.A, “Análisis y evolución del nodo contaminante denominado Laguna Azul, en los alrededores de la ciudad de La Rioja", V Simposio iberoamericano de Ingeniería de Residuos Sólidos. Primer seminario nacional de residuos sólidos, Universidad Nacional de Cuyo, Mendoza, Argentina, 2013.

Mamaní, M., Huespe, J., Moreno Ravelli, R. y Dematte, R., "Contaminación en un sitio urbano de la ciudad de La Rioja, Argentina. Análisis de riesgo", Multekina, vol. 1, núm. 19, pp. 21-31, CRICyT, Mendoza, Argentina, 2010.

Massiris Cabeza, A., "Ordenamiento territorial, Región y procesos de construcción regional", Revista Perspectiva Geográfica, Programa de Estudios de Posgrado en Geografía (EPG), núm. 1, pp. 7-87, Universidad Pedagógica y Tecnológica de Colombia (UPTC), Instituto Geográfico Agustín Codazzi, 1997.

Varela, Ricardo; Basei, Miguel A.S. y Pereyra Claudia, "Datación U-PB del granito Paiman, Sierra de Paiman, Chilecito, La Rioja", Revista de la Asociación Geológica Argentina, vol. 63, núm. 1, 2008. 